Reduced diphosphopyridine nucleotide oxidase is a particulate enzyme complex isolated by Green and Mackler ${ }^{12}$ from beef mitochondria associated with the electron transport particle which will mediate the following reaction :

$$
\mathrm{DPNH}+\mathrm{H}^{+}+\frac{1}{2} \mathrm{O}_{2} \rightarrow \mathrm{DPN}^{+}+\mathrm{H}_{2} \mathrm{O}
$$

The complete system, which is antimycin-sensitive and will not reduce ferricytochrome $c$ by reduced diphosphopyridine nucleotide nor oxidize ferrocytochrome $c$ by oxygen, was originally claimed not to contain cytochrome $c$, but this is now in doubt. Treatment of the electron transport particle by trypsin and deoxycholate removes the capacity of reduced diphosphopyridine nucleotide to react with oxygen, but it will then catalyse cytochrome c reactions. The degraded electron transport particle contains flavin, cytochrome $b$ type hæm, cytochrome oxidase hæm, copper and non-hæm iron.

Metals regulating alternative pathways of electron transfer. When Pseudomonas fluorescens is grown under low oxygen tension, large amounts of cytochrome, catalase and cytochrome peroxidase are produced, but flavoprotein systems, including diaphorase and nitrate and nitrite reductases, are depleted. At high oxygen tension, however, the reverse is true, namely, low production of iron enzymes and a substantial increase in the flavoproteins. The molybdenum requirement of the cells is greater and that for iron less at high oxygen tension. Thus the terminal electron transfer system is dependent on molybdenum in vigorously aerated cells, whereas an iron system predominates when oxygen is minimal ${ }^{14}$. In a riboflavin-requiring mutant of Neurospora, when the vitamin is deficient the production of iron enzymes and the iron requirement is greater, whereas flavoproteins and the molybdenum content of cells are less than when it is grown at optimal riboflavin levels. Nitrate is the terminal acceptor at optimal vitamin status, whereas oxygen serves when riboflavin is deficient ${ }^{15}$.
Metallo-dehydrogenases and other enzymes. Zinc has been identified as a constituent of alcohol, glutamic and lactic dehydrogenases based on inhibitor studies and emission spectrochemical analysis of the crystalline enzymes. Using the same criteria, glucose 6-phosphate and glycerophosphate and malic dehydrogenases were also shown to contain zinc, but copper and iron were also present in some of these enzymes in substantial amounts. The suggestion that all pyridine nucleotide-linked dehydrogenases are metallo-enzymes ${ }^{16}$ lacks direct experimental proof.

Other enzymes dependent on zinc include carboxypeptidase from pancreas ${ }^{16}$ and hexokinase from Neurospora ${ }^{17}$. Uricase has been shown to contain copper ${ }^{18}$.

1 Vennesland, B., and Westheimer, F. H., in "Mechanism of Enzyme Action", edited by McElroy, W. D., and Glass, B., p. 357 (Johns Hopkins Univ. Press, 1954).

"Nason, A., in "Inorganic Nitrogen Metabolism", edited by McElroy, W. D., and Glass, B., p. 109 (Johns Fopkins Univ. Press, 1956). ${ }^{3}$ Nicholas, D. J. D., and Stevens, H. M., ibid., p. 178.

4 Nicholas, D. J. D., and Scawin, J. H., Nature, 178, 1474 (1956).

s Taniguchi, S., Sato, R., and Egami, F., in "Inorganic Nitrogen Metabolism", edited by McElroy,

- Medina, A., and Nicholas, D. J. D., Biochim. Biophys. Acta, 23, 440 (1957); Nature, 179, 533 (1957).

McElroy, W. D., and Spencer, D., in "Inorganic Nitrogen Metsbolism", edited by McElroy, W. D., and Glass, B., p. 137 (Johns Hopkins Univ. Press, 1956).

- Najjar, V. A., and Chung, C. W., ibid., p. 260.

Lees, H., "Biochemistry of Autotrophic Bacteria", p. 49 (Butter. worths Sci. Pub., London, 1955).

${ }^{10}$ Burris, R. H., in "Inorganic Nitrogen Metabolism", p. 316.

11 Virtanen, A. I., in Conférences et Rapports, 3ème Congrés Int. Biochim. Bruxelles, p. 425 (1958).

1 Mahler, H., "Adv, in Enzym.", 17, 233 (1956).

13 Avis, P. G., Bergal, F., and Bray, R. C., J. Chem. Soc., 1100 (1955); 1212 and 1219 (1956).

is Kaplan, N. O., Bact. Rev., 19, 9, 235 (1955).

15 Nicholas, D. J. D., J. Gen. Microbiol., 15, 470 (1956). 16 Vallee, B. L., Hoch, F. L., Adelstein, S. J., and Wacker, W. E. C.,
$J$. Amer. Ćhem. Soc., 78, 5879 (1956).

17 Medina, A., and Nicholas, D. J. D., Nature, 179, 87 (1957).

18 Mahler, H. R., Baum, H. M., and Hubscher, G., Science, 124, 705 (1956).

\title{
RELATIONS BETWEEN THE SUN AND THE IONOSPHERE
}

\begin{abstract}
A GEOPHYSICAI discussion held at the Royal Astronomical Society on February 22 was devoted to "The Relations between the Sun and the Ionosphere". It was divided into two parts.

In the first part, Dr. M. A. Ellison, Dr. H. Elliot, Mr. C. D. Watkins, Mr. C. M. Minnis and Dr. K. Weekes read short papers on "The Great Solar Flare of 1956 February 23". On February 23, 1956, observers in Japan saw a flare of magnitude $3+, 20^{\circ}$ from the west limb of the Sun, which started at 0331 U.T., and reached a maximum, as judged by its line-width, at $0342 \pm 2$ U.T. It occurred in a complicated spot group which had been changing and developing as it moved across the solar disk. The flare was bright enough to be seen in white light and was followed by a large surge prominence.

The flare was accompanied by a great increase of cosmic rays over both the light and dark sides of the Earth. In England the total cosmic ray flux at ground-level reached a maximum, equal to twice its normal value, at 0350 U.T. 'There was even a significant increase at the equator.
\end{abstract}

Radio observations made on the sunlit side of the Earth showed that there the ionosphere was disturbed by the flare in the usual way. A marked increase of absorption was recorded at Singapore $\left(1^{\circ} \mathrm{N}, 1^{\circ} 104^{\circ} \mathrm{E}.\right)$ and a 'radio fade out' was reported on commercial radio links. Extra-terrestrial noise recorded at Ahmedabad ( $23^{\circ} \mathrm{N} ., 13^{\circ} \mathrm{E}$.) was strongly absorbed at 0330 U.T. Magnetic 'crochets' were observed at Singapore and Kodaikanal. The phase of waves of frequency $16 \mathrm{kc} . / \mathrm{s}$. received from Station $G B R$ (England) at Wellington $\left(41^{\circ} \mathrm{S} ., 175^{\circ} \mathrm{E}\right.$.) showed a sudden change starting at 0335 U.T. and reaching its maximum at 0415 U.T.

All these radio phenomena are of a type familiar on the sunlit side of the Earth during a sudden ionosphere disturbance. After the flare the critical frequencies of the $E$ - and $F^{2}$-layers were found to be greater than usual. This phenomenon had previously been noticed only for the most intense flares.

The unique feature of this flare was that it produced marked effects in the ionosphere on the dark side of the Earth. No previous flare has ever been 
known to do this. The effect on the derk ionosphere was most clearly evident in the following ways : (a) Long and very long waves, traversing oblique paths, were strongly absorbed. For example, the strength of atmospherics, received on frequencies greater than $10 \mathrm{kc} . / \mathrm{s}$. in high and temperate latitudes, decreased suddenly near 0345 U.T. and remained small until at least local sunset on February 23. The decrease seemed to be smaller at low latitudes, and the strength of atmospherics received at Rabat $\left(34^{\circ} \mathrm{N} ., 6 \cdot 8^{\circ} \mathrm{W}\right.$.) was unaltered. Waves from distant commercial transmitters in the frequency range 70-240 kc./s. were suddenly and strongly absorbed at 0345 v.T. in temperate latitudes. (b) The absorption of short waves reflected vertically started to increase near 0345 J.T. and the increase was greater at higher latitudes. The increased absorption lasted longer at higher latitudes and near the auroral zone it lasted for $50 \mathrm{hr}$. or more. (c) The height of reflexion of very long waves $(16 \mathrm{kc} . / \mathrm{s}$.$) received from Station$ $G B R$ at Cambridge $\left(52^{\circ} \mathrm{N} ., 0^{\circ}\right.$ E.), after nearly vertical reflexion, decreased suddenly by about $8 \mathrm{~km}$. at 0345 U.T., reached a minimum (about $80 \mathrm{~km}$.) at $0405 \mathrm{U.T.}$, and then increased until 0600 U.T. The amplitude of these waves was not altered.

These phenomena on the dark side of the Earth seem to indicate that the ionization at heights near 80 or $90 \mathrm{~km}$. was suddenly increased, at about 0345 U.T., and that the increase was greater, and persisted longer, at higher latitudes. The absence of extra absorption of the $16 \mathrm{kc} / \mathrm{s}$. waves received at Cambridge, and the limited decrease in the height of their reflexion, seem to show that there was little increase of ionization below $80 \mathrm{~km}$. at those latitudes.

The ionospheric effect was so sudden that it was possible to state with accuracy that it started at $0345 \pm 1$ ठ.T. This time was $3 \mathrm{~min}$. after the peak intensity of the flare and $14 \mathrm{~min}$. after its start. If it is supposed that the effect on the ionosphere was produced by a stream of particles which left the Sun either at the start of the flare, or at its peak, then it would have to travel with a mean velocity of either $0.37 c$ or $0.73 c$ (where $c$ is the velocity of light). The cosmic ray effect was observed at the same time as the ionospheric effect, and there are difficulties in explaining how cosmic rays which could be detected at the ground near the equator could have had such a small velocity. One suggestion was that they did not travel straight from the Sun but had been reflected to the Earth from somewhere else.

The radio observations indicate that a second rather slower increase of ionization occurred near 0530 ए.T. and was probably more intense at higher latitudes.

The behaviour of the $D$-region at sunrise on February 23 was different from normal. This difference was evident in the variations of amplitude and phase of waves of low and very low frequency, and in the absorption of high-frequency waves observed at vertical incidence. In particular, sunrise effects were noticeable earlier than usual, when the solar zenith angle had a value of about $98^{\circ}$. It seems probable that the $D$-region had been altered by the effects of the flare in some way which allowed the first light from the Sun to produce ionization. Perhaps a large number of negative ions had been formed, from which the electrons were removed by the first light incident at sunrise.

Explanations of the phenomena on the dark side of the Earth meet with the difficulty that, if incident charged particles are presumed to have sufficient energy to reach low latitudes in spite of the deviating effect of the Earth's magnetic field, then they would have so much energy that they would produce their maximum ionization low down in the atmosphere, whereas the radio observations show that this was produced in the $D$-region. Dr. Elliot suggested that the primary particles in the stream might be single ionized helium atoms, with an energy of a few $\mathrm{BeV}$. which would be sufficient to carry them to these latitudes, and that when they entered the atmosphere an electron was removed, and travelled with the same velocity. Because of its smaller mass this electron would have an energy of only a few hundred $\mathrm{keV}$. and would be absorbed near the $D$-region, where it would produce most of its ionization.

An ionosphere storm was observed on February 25 with a 'sudden commencement' at 0310 U.T. It seems likely that this was the result of the flare of February 23, but, since there was so much visible activity on the Sun during the days immediately before and after the flare, the two cannot be unequivocably related. The ionosphere storm was of the usual type and was not abnormal.

In the second part of the discussion Prof. C. W. Allen, Mr. G. M. Brown, Mr. C. M. Minnis and Mr. M. Ryle contributed short papers on "The Solar Cycle Variation of the Sun's Ionizing Radiation". 'This radiation, which determines the density of ionization in the ionosphere, is supposed to consist of a 'background' which may vary smoothly over the solar cycle, together with a 'slowly varying' com. ponent which comes from the local active centres associated with such phenomena as sunspots, faculæ, and emission of the coronal green line. The problem is to separate these two components by considering the way in which the ionization varies. An analogous problem presents itself in radio astronomy where the decimetre wave radiation is observed, and in that case it has been possible to separate out a back. ground and a slowly varying component.

One method of separating the two components is to plot, at one phase of the solar cycle, measures of the radiation against simultaneous measures of solar activity. Extrapolation of the resulting curve to zero activity gives the magnitude of the background component at that phase of the cycle. Although there are difficulties in applying this method, it has given valuable results for radio astronomy.

The best index of the intensity of the ionizing radiation seems to be the $E$-layer character figure $S$ given by $S=(f E)^{4} / \cos \chi$ at places where it has been shown that $\cos \chi \propto(f E)^{4}$. This relation is known to be fairly accurate for the seasonal variation of noon observations made in England. Mr. Brown, working with Dr. W. J. G. Beynon, has investigated how $S$ varied with the sunspot number $R$. From a study of the amplitude of 27-day periodicities in $S$ and $R$, and also of the solar cycle increase in the average value of $S$, they have estimated that the background variation increases by about 100 per cent as $R$ increases from 0 to 150 , and the slowly varying component when $R=150$ is about one-quarter of the total ionizing radiation.

These changes of the background and the slowly varying components of the ionizing radiation are roughly the same as the corresponding changes observed in the solar radio noise measure on a wavelength of $10 \mathrm{~cm}$. It has also been shown that the dayto-day variations of the radio noise follow quite closely those of the $E$-region character figure. 
During the eclipse of June 30, 1954, the Sun was unusually inactive, and it was possible to deduce the distribution of sources of ionizing radiation across it. It was found that there was an intensification near the east and west limbs, and a weakening near the poles. The results coincided closely with the distribution of decimetre radio noise radiation over the solar disk.

The $E$-layer character figure and the intensity of the 10-cm. wave-length noise radiation appear to be closely related as regards their variation from day to day, their variation with the solar cycle, and their variation over the solar disk. It cannot yet, however, be concluded that both types of radiation have a common origin. Recent estimates of how the temperature varies with height in the solar atmosphere suggest that the chromosphere and lower corona, which are responsible for most of the decimetre wave emission, would not make as important a contribution to the ionizing radiation as would the Lyman continuum from photospheric levels. A comparison of the ionospheric curves with those of solar noise emission on 3,10 and $20 \mathrm{~cm}$. wave-lengths might enable the height of emission of the ionizing radiation to be established.

\section{OBITUARIES}

Sir Percival Hartley, C.B.E., F.R.S.

Sir Percival Harteey, formerly director of the Department of Biological Standards at the National Institute for Medical Research, London, died in London on February 16 at the age of seventy-five. $\mathrm{He}$ was born on May 28, 1881, at Calverly in Yorkshire and was educated at the University of Leeds, where he graduated B.Sc. in 1905 . With a Grocer's Company Research Scholarship he went to the Lister Institute of Preventive Medicine, London. In 1909 he obtained a D.Sc. in the University of London and joined the staff of the Imperial Bacteriological Laboratory at Muktesar in India. In 1913 he returned to the Lister Institute.

During the First World War he served as a captain in the R.A.M.C., and in 1917 was awarded the Military Cross. On demobilization he spent two years at the Wellcome Research Laboratories. It was during this time that he began the study of diphtheria prophylactics with which his name will always be associated.

In 1922 he joined the staff of the National Institute for Medical Research, where he became the director of the new Department of Biological Standards, an appointment he held until he retired in 1946. During this time, Percival Hartley, more than any other man, was responsible for the introduction of the International Biological Standards. $\mathrm{H}_{\Theta}$ educated world opinion as to their need. He provided not only the immunological standards but also, frequently, methods of standardization as well.

There is no doubt that the years he spent at the National Institute for Medical Research were both the happiest and most productive of his life. His work on the prevention of diphtheria is well known, but it is seldom appreciated that the regulations which he formulated to be used in Great Britain guaranteed the purity, safety and potency of immunological reagents in general and diphtheria prophylactics in particular.

It was remarkable that with all his administrative responsibilities and obligations he managed to find time for research. Among the many subjects he studied were the role of non-specific factors on antibody production, the nature of anaphylaxis, the care and maintenance of laboratory animals, the standardization and quality of media. Hartley's broth is world known.

During this time he received many honours. In 1927 he was awarded the William Julius Mickle Fellowship of the University of London. In $1936 \mathrm{he}$ was appointed a Commander of the British Empire; in 1937 he was elected to the Fellowship of the Royal Society ; in 1944 he was knighted. When he retired in 1946 he laid down his heavy routine duties, but a new phase in his career developed. He held a series of appointments. During 1946-48 he was Wandsworth Fellow of the London School of Hygiene and Tropical Medicine. During 1948-49 he was at the Sir William Dunn School of Pathology in Oxford. During 1949-53 he returned to the Lister Institute. $\mathrm{He}_{\mathrm{e}}$ was a member of the British Pharmacopœia Commission from 1933 until 1948, and he served on the Medical Research Council during 1949-53. Throughout this time he continued his research-in particular, the effect of purification of antitoxin on its ability to cross the placental barrier.

Hartley taught students and staff alike. His teaching was simple and practical. He spoke with authority, as one who had spent a life-time in the laboratory and had grown up with the great men and great events of the world of science. An enthusiast himself, by example he made his students enthusiastic.

In 1948 his old University of Leeds conferred on him the honorary degree of D.Sc. In his oration he talked of the history of diphtheria prophylactics and treatment. I remember the care with which he prepared his lecture; each lantern slide produced a flood of recollection. Much of the story was from his own experience.

This précis of the successful career of a brilliant man, of his achievements and of the honours he received, gives no indication of his courtesy, his charm, the tremendous whole-hearted warmth with which he greeted his friends; his selflessness, his modesty and his kindness to his juniors. A sensitive man, who hesitated to protest unless in defence of his scientific beliefs or high principles, he was capable of a fine flow of invective when faced with stubborn inefficiency that would not yield to gentler measures. But even then he could not maintain his anger and sought the earliest opportunity to make amends.

$\mathrm{He}$ married Miss Olga Parnell in 1920. Lady Hartley died in 1950. $\mathrm{He}$ is survived by two $\begin{array}{ll}\text { daughters of the marriage. } & \text { D. A. LONG }\end{array}$

\section{Mr. A. G. Davis}

Arthur George Davis, who died at his London home on March 1 at the age of sixty-four, had long played an invaluable and peculiar part in the progress of geology in south-erst England. - He was primarily an enthusiastic and highly successful collector of fossils whose zeal did not wane with the passing years. Many a fruitful temporary section would have 